\title{
Antimicrobial Drugs Susceptibility Pattern of Bacterial Pathogens Isolated from Cases of Tubotympanic Type of Chronic Suppurative Otitis Media (CSOM) in Tripoli-Libya
}

\author{
*Corresponding Author \\ Dr. Nagat Mohamed Saeed

\section{Article History} \\ Received: 27.02 .2021 \\ Accepted: 18.04 .2021 \\ Published: 30.04 .2021
}

Khalled M Saeed ${ }^{1}$, Nagat M Saeed ${ }^{2 *}$, Fatma M Ben Rabha ${ }^{2}$, Lamees Ben Saad $^{2}$, Samia A Hassan $^{2}$

${ }^{\mathrm{T}}$ Health Centre Suleiman Khater, Tripoli - Libya

${ }^{2}$ Department of pharmacology, Faculty of Medicine, University of Tripoli, Tripoli - Libya

\begin{abstract}
Chronic suppurative otitis media is persistent and insidious disease that often lead to destructive changes and irreversible sequelae if not treated properly. The study aimed to find the pattern of antimicrobial drug susceptibility of the pathogenic microorganisms causing tubotympanic type of CSOM. The study was conducted in 65 patients with tubotympanic type of disease attending the (ENT) OPD clinic at Central Hospital-Tripoli, Libya. Drug susceptibility testing was carried out using a Kirby Bauer disc diffusion method. Pathogens were isolated from $96.9 \%$ patients with a total of 95 , of the 95 isolates, $(88.4 \%)$ were bacterial pathogen and $(11.6 \%)$ were fungal. The most predominant isolates were Pseudomonas aeruginosa (31.6\%), followed by Staphylococcus aureus $(25.3 \%)$ and Proteus mirabilis $(8.4 \%)$. The antimicrobial profile of the major isolates of Pseudomonas aeruginosa revealed maximum sensitivity to ciprofloxacin $(93.3 \%)$, followed by polymyxin $(90.0 \%)$, ceftazidime $(83.3 \%)$ and amikacin $(73.3 \%)$. Whereas the antimicrobial profile of the isolates Staphylococcus aureus was revealed maximum sensitivity to ciprofloxacin (95.8\%), followed by amoxil/clavulanic acid (83.3\%), cephalexin, gentamicin, chloramphenicol (79.2\%) each, neomycin (75.0\%) and erythromycin $(70.8 \%)$. On the other hand Proteus mirabilis showed high level of sensitivity to ciprofloxacin, ceftazidime (100\%) each, followed by amoxil/clavulanic acid, amikacin (87.5\%) each, gentamicin, neomycin, trimethoprim sulphamethoxazole $(75.0 \%)$ each. Our finding highlight the importance of a continuous and periodic evaluation of microbial pathogens causing tubothympanic CSOM and their susceptibility patterns to antimicrobial drugs, this will guide the clinician for choosing the appropriate treatment regimen and prevention of the emergence of resistant strain as well as can minimize complication that require surgery.
\end{abstract}

Keywords: chronic suppurative otits media, CSOM, Antimicrobial susceptibility testing, Pseudomanas aeruginosa, Staphylococcus aureaus, Proteus mirabilis.

\section{INTRODUCTION}

Chronic suppurative otitis media (CSOM) is a persistent and insidious disease that often leads to destructive changes and irreversible sequelae if not treated properly. Its characterized by chronic inflammation of middle ear and recurrent or persistent discharge (otorrhoea) over 2 to 6 week through a perforation in the tympanic membrane [1, 2]. The recurrence and persistent infection is the common causes of deafness and permanent perforation of tympanic membrane [3].

CSOM is usually characterized by a polymicrobial infection often associated with an underlying anatomic or functional abnormality. Initially, CSOM can be a result of previous acute otitis media (AOM) with spontaneous perforation of the tympanic membrane or anatomic abnormalities with associated complication [4]. CSOM is usually of safe/tubotympanic type in developing countries, it is characterized by a central perforation of the pars tensa with the inflammatory process affecting the mucos of the middle ear cleft. Atticoantral/ unsafe type are typified by marginal perforation of the posterosuperior pars tensa or pars flaccida $[5,6]$.

Copyright (C) 2020 The Author(s): This is an open-access article distributed under the terms of the Creative Commons Attribution 4.0 International License (CC BY-NC 4.0) which permits unrestricted use, distribution, and reproduction in any medium for noncommercial use provided the original author and source are credited. 
All cases of CSOM including those described as safe type of disease can be associated with complication [7]. A wide range of microorganisms both aerobic and anaerobic may isolated from cases of CSOM whether atticoantral or tubotympanic disease. The proportions of different organisms isolated vary from study to study depending on the geographic area and other factors [8, 9]. Empiric treatment of ear infection is not always appropriate since drug susceptibility patterns change overtime and empiric antibiotic therapy may not be effective at times and could contribute to development of antimicrobial resistance in the long run $[10,11]$. Thus knowledge of the major bacterial pathogens and their antibiotic susceptibility patterns for both atticoantral or tubotympanic type of CSOM is very important it will guide the clinician for choosing the appropriate treatment regimen and prevention of the emergence of resistant strain as well as can minimize complication that require surgery. Therefore, this study aimed to find the pattern of antimicrobial drug susceptibility of the pathogenic microorganisms isolated from cases of tubotympanic type of CSOM. This can be used as a guideline in prescribing the appropriate treatment.

\section{Patients and Methods}

The study was conducted in 65 patients with tubotympanic type of CSOM attending the Ear, Nose, Throat (ENT) OPD clinic at Central Hospital-Tripoli. The patients who had chronic pus discharging from one or both ears for at least 3 months from all age group were included in this study. These patients had received no antibiotic treatment during the previous 3 days, and had not suffered any otitis externa. Each patient was subjected to a full otologic examination, and the otic secretion (purulent discharge) was collected under sterile condition. The ear swabs were immediately sent to the microbiology laboratory for microbiological studies. Ethical committee approval was obtained before starting the study.

\section{Isolation and identification of pathogens}

The ear swab samples were cultured on blood agar, chocolate agar, gentamicin blood agar, MacConkeys agar, mannitol salt agar, neutrient agar with X and V factors, and Sabourads agar (Oxoid, UK) and then incubated aerobically and anaerobically at $37^{\circ} \mathrm{C}$. The isolates grown were identified macroscopically and microbiologically and then identified biochemically by standard technique as described previously in Monica in1984 [12] and confirmed by the API 20 E, and API 20 NE (Biomerieux-France). Slidex Strepto kit (BiomerieuxFrance) was used to confirm the streptococci groups.

\section{Antimicrobial susceptibility testing}

Antimicrobial susceptibility patterns were carried out using Kirby Bauer disc diffusion technique on MuellerHinton agar (Oxoid, UK) [12, 13]. The antimicrobial agents used included: ampicillin $(10 \mu \mathrm{g})$, amoxicillin/clavulanic acid $(30 \mu \mathrm{g})$, cephalexin $(30 \mu \mathrm{g})$, ceftazidime $(30 \mu \mathrm{g})$, gentamicin $(10 \mu \mathrm{g})$, amikacin $(30 \mu \mathrm{g})$, polymyxin $(300$ units $)$, neomycin $(30 \mu \mathrm{g})$, trimethoprim sulphamethoxazole $(25 \mu \mathrm{g})$, chloramphenicol $(10 \mu \mathrm{g})$, erythromycin $(15 \mu \mathrm{g})$, tetracycline $(30 \mu \mathrm{g})$ and ciprofloxacin $(5 \mu \mathrm{g})$. All the antimicrobials used for the study were obtained from Oxoid Ltd., Basingstoke, Hampshire, UK (Oxoid, UK). Reference strains of Pseudomonas aeruginosa (NCTC6749) and Staphylococcus aureus (NCTC 4163) were used for quality control for antimicrobial susceptibility tests.

\section{Statistical Analysis}

Descriptive statistics such as frequency, percentage and cross tabulation were used to present the findings. Chisquare test and SPSS version 21 software wherever appropriate was performed to evaluate the presence of statistically significant association between potential variables. P-values less than 0.05 were considered as statistically significant.

\section{RESULTS}

Sixty five patients with tubotympanic CSOM were enrolled in the study. The demographic and clinical characteristics of patients are shown in Table 1 . Thirty nine patients were females representing $(60 \%)$ and $26(40 \%)$ were males; with female to male ratio 1.5: 1 . The peak age group was between (21 - 30 years) representing $40 \%$ of patients, followed by age group (31 - 40 years) which representing $29.2 \%$ and the lowest was for age groups $(\leq 10$ years) which representing $(6.2 \%)$. In all age groups female were more commonly affected than male patients, but the relation was not found to be statistically significant. Regarding the geographical distribution of patients with tubotympanic CSOM, out of 65 patients, 47 patients representing $72.3 \%$ were local inhabitants of Tripoli city and 18 patients representing $27.7 \%$ came from other Libyan cities. The duration of tubotympanic CSOM in our patients shows that, the highest group 42 $(64.6 \%)$ is suffering from disease for more than two years while, the lowest group $8(12.3 \%)$ has CSOM for less than one year. It is noteworthy that many of the older patients gave a history that their chronic ear discharge dated back to early childhood. Of the study patients 45 (69.2\%) had unilateral CSOM and 20 (30.8\%) patients with bilateral CSOM at the time of first consultation (Table 1).

In present study, pathogens were isolated from 63 (96.9\%) patients with a total of 95 isolates. Pure culture were isolated from $32(49.2 \%)$ patients, mixed culture (isolation of two or more different microorganisms in the same specimen) were isolated from $31(47.7 \%)$ patients, while $2(3.1 \%)$ patients showed no growth or sterile culture. From our 
results we observed that the combinations of isolates did not show any consistent pattern. Of the 95 isolates, 84 ( $88.4 \%)$ were bacterial pathogen and $11(11.6 \%)$ were fungal.

The predominant isolate from cases of tubotympanic type of CSOM was Pseudomonas aeruginosa 30 (31.6\%), followed by Staphylococcus aureus $24(25.3 \%)$ and Proteus mirabilis 8 (8.4\%). Fungi were also isolated; the most common was Candida species 6 (6.3\%), followed by Aspergillus species 5 (5.3\%) while the other bacterial pathogens were the less commonly involved (Table 2).

In our study, the results of antimicrobial drugs susceptibility patterns of bacterial pathogens isolated from cases of tubotympanic CSOM were shown in Table. 3. The antimicrobial profile of the major isolates of Pseudomonas aeruginosa revealed maximum sensitivity to ciprofloxacin $28(93.3 \%)$, followed by polymyxin $27(90.0 \%)$, ceftazidime $25(83.3 \%)$ and amikacin $22(73.3 \%)$. Whereas the antimicrobial profile of the isolates Staphylococcus aureus was revealed maximum sensitivity to ciprofloxacin 23 (95.8\%), followed by amoxil/clavulanic acid 20 (83.3\%), cephalexin, gentamicin, chloramphenicol $19(79.2 \%)$ each, neomycin $18(75.0 \%)$ and erythromycin $17(70.8 \%)$. On the other hand Proteus mirabilis showed high level of sensitivity to ciprofloxacin, ceftazidime 8 (100\%) each, followed by amoxil/clavulanic acid, amikacin $7(87.5 \%)$ each, gentamicin, neomycin, trimethoprim sulphamethoxazole $6(75.0 \%)$ each. The other isolates including; providencia stuartii, Providencia rettgeri, Klebsiella pneumonia, Escherichia coli, Enterobacter cloacae and Morganella morgana shows high sensitivity to ciprofloxacin and amikacin 15 (100) each, followed by ceftazidime $13(86.7 \%)$, gentamicin, polymyxin, neomycin, trimethoprim sulphamethoxazole $12(80.0 \%)$ each followed by cephalexin $11(73.3 \%)$.

Table-1: Demographic and clinical characteristic of patients with tubotympanic CSOM

\begin{tabular}{|l|l|}
\hline Study variables & Number and percentage of patient N (\%) \\
\hline Gender & $26(40)$ \\
\hline Male & $39(60)$ \\
\hline Female & $65(100)$ \\
\hline Total & $4(6.2)$ \\
\hline Age group & $8(12.3)$ \\
\hline$\leq 10$ & $26(40)$ \\
\hline $11-20$ & $19(29.2)$ \\
\hline $21-30$ & $8(12.3)$ \\
\hline $31-40$ & $65(100)$ \\
\hline $40>$ & $47(72.3)$ \\
\hline Total & $18(27.7)$ \\
\hline Geographic distribution \\
\hline Tripoli city & $65(100)$ \\
\hline Out of Tripoli city & $8(12.3)$ \\
\hline Total & $15(23.1)$ \\
\hline Duration of disease (years) \\
\hline$<1$ & $42(64.6)$ \\
\hline $1-2$ & $65(100)$ \\
\hline$>2$ & $45(69.2)$ \\
\hline Total & $20(30.8)$ \\
\hline Distribution of patients with unilateral and bilateral CSOM \\
\hline Unilateral CSOM & $65(100)$ \\
\hline Bilateral CSOM & \\
\hline Total & \\
\hline
\end{tabular}

Table-2: Distribution of different micoorganisms isolates from cases of tubotympanic type of CSOM

\begin{tabular}{|l|l|}
\hline Microorganisms & $\begin{array}{l}\text { Number of isolates and Percentage (\%) } \\
(\mathbf{N = 9 5 )}\end{array}$ \\
\hline Psedomonas aeruginosa & $30(31.6)$ \\
\hline Staphylooccus aureus & $24(25.3)$ \\
\hline Proteus mirabilis & $8(8.4)$ \\
\hline Candida species & $6(6.3)$ \\
\hline Aspergillus species & $5(5.3)$ \\
\hline Providencia stuartii & $4(4.2)$ \\
\hline Klebsiella pneumonia & $3(3.2)$ \\
\hline
\end{tabular}




\begin{tabular}{|l|l|}
\hline Microorganisms & $\begin{array}{l}\text { Number of isolates and Percentage (\%) } \\
\mathbf{( N = 9 5 )}\end{array}$ \\
\hline Bacteroides melaninogenicus & $3(3.2)$ \\
\hline Escherichia coli & $3(3.2)$ \\
\hline Providencia rettgeri & $2(2.1)$ \\
\hline Enterobacter cloacae & $2(2.1)$ \\
\hline Peptococcus species & $2(2.1)$ \\
\hline Morganella morgani & $1(1.1)$ \\
\hline Streptococcus pneumoniae & $1(1.1)$ \\
\hline Staphylococcus epidermidis & $1(1.1)$ \\
\hline
\end{tabular}

Table-3: Antimicrobial drugs susceptibility patterns of bacterial pathogens isolated from cases of tubotympanic CSOM. (Data represent numbers and percentage)

\begin{tabular}{|l|l|l|l|l|}
\hline Antimicrobial agents & $\begin{array}{l}\text { Psedomonas } \\
\text { aeruginosa } \\
(\mathbf{n = 3 0})\end{array}$ & $\begin{array}{l}\text { Staphylooccus } \\
\text { aureus } \\
(\mathbf{n = 2 4})\end{array}$ & $\begin{array}{l}\text { Proteus } \\
\text { mirabilis } \\
(\mathbf{n = 8})\end{array}$ & $\begin{array}{l}\text { others* } \\
\mathbf{n = 1 5})(\end{array}$ \\
\hline Ampicillin $(10 \mu \mathrm{g})$ & $\mathrm{NT}$ & $7(29.2)$ & $3(37.5)$ & $4(26.7)$ \\
\hline Amoxil/clavulanic acid $(30 \mu \mathrm{g})$ & $\mathrm{NT}$ & $20(83.3)$ & $7(87.5)$ & $7(46.7)$ \\
\hline Cephalexin $(30 \mu \mathrm{g})$ & $\mathrm{NT}$ & $19(79.2)$ & $5(62.5)$ & $11(73.3)$ \\
\hline Ceftazidime $(30 \mu \mathrm{g})$ & $25(83.3)$ & $\mathrm{NT}$ & $8(100)$ & $13(86.7)$ \\
\hline Gentamicin $(10 \mu \mathrm{g})$ & $11(36.7)$ & $19(79.2)$ & $6(75.0)$ & $12(80.0)$ \\
\hline Amikacin $(30 \mu \mathrm{g})$ & $22(73.3)$ & $\mathrm{NT}$ & $7(87.5)$ & $15(100)$ \\
\hline Polymyxin $(300 \mathrm{units})$ & $27(90.0)$ & $11(45.8)$ & $\mathrm{NT}$ & $12(80.0)$ \\
\hline Neomycin $(30 \mu \mathrm{g})$, & $9(30.0)$ & $18(75.0)$ & $6(75.0)$ & $12(80.0)$ \\
\hline Trimethoprim sulphamethoxazole $(25 \mu \mathrm{g})$ & $\mathrm{NT}$ & $\mathrm{NT}$ & $6(75.0)$ & $12(80.0)$ \\
\hline Chloramphenicol $(10 \mu \mathrm{g})$ & $\mathrm{NT}$ & $19(79.2)$ & $5(62.5)$ & $8(53.3)$ \\
\hline Erythromycin $(15 \mu \mathrm{g})$ & $\mathrm{NT}$ & $17(70.8)$ & $\mathrm{NT}$ & $\mathrm{NT}$ \\
\hline Tetracycline $(30 \mu \mathrm{g})$ & $\mathrm{NT}$ & $16(66.7)$ & $\mathrm{NT}$ & $5(33.3)$ \\
\hline Ciprofloxacin $(5 \mu \mathrm{g})$ & $28(93.3)$ & $23(95.8)$ & $8(100)$ & $15(100)$ \\
\hline
\end{tabular}

Others* Includes: Providencia stuartii $(n=4)$, Providencia rettgeri $(n=2)$, Klebsiella pneumonia $(n=3)$, Escherichia coli $(\mathrm{n}=3)$, Enterobacter cloacae $(\mathrm{n}=2)$, Morganella morgana $(\mathrm{n}=1)$.

\section{DISCUSSION}

Chronic suppurative otitis media (CSOM) is a very common disease that should be carefully treated, as severe life threatening complications can develop. Therefore, it is important to identify the microbial pathogens causing CSOM and knowledge their antimicrobial susceptibility patterns, for proper management of CSOM. In present study the demographic and clinical character of patients with tubotympanic CSOM were carried out in 65 patients. The results showed that $60 \%$ patient was females and $40 \%$ were males. In all age groups female were more commonly affected than male patients, but the relation was not found to be statistically significant. This result which is in accordance with previous study by Govindaraj et al, whose study had female (60\%) and male (40\%) [14]. Whereas Shyamala et al whose study showed male patients were predominance 57\% [15]. In our study population we had more adult patient with CSOM than pediatric patients. The reason may be that our hospital mainly treats adults. However, this probably represents a sampling bias and consequently no significant conclusion can be drawn from the frequency of CSOM in these two different age groups. In the present study the peak incidence of chronic ear discharge was in the age group (21 - 30) years, representing, $40 \%$ from 65 patients, this finding was congruent with another study which reported that the majority of patients (22.7\%) were aged 21-30 years [16]. While this finding was not congruent with another study which reported that the highest disease rate 25.9\% occurred between age group (51-60) year [17]. In our study a high proportion of the older patients said they had discharging ears for as long as they could recall. This could mean that their chronic ear started in the early of their life.

In present study, microbial pathogens were isolated from $96.9 \%$ patients with a total of 95 isolates. Pure culture were isolated from $49.2 \%$ patients, mixed culture were isolated from $47.7 \%$ patients we observed that the combinations of isolates did not show any consistent pattern. However, $3.1 \%$ patients showed no growth or sterile culture. This could related to our patients may receive multiple or incomplete antibiotic courses which may lead to sterile culture.

In the present work the most common bacterial pathogens isolated from the middle ear discharge of patients with tubotypanic type of CSOM, were Pseudomonas aeruginosa (31.6\%), and followed by Staphylococcus aureus $(25.3 \%)$ and Proteus mirabilis $(8.4 \%)$. The aerobic microbes isolated in this study were closely similar to those reported 
elsewhere [18-21]. Others Xu et al. [17] reported that Staphylococcus aureus is the most common isolate 44.9\% followed by Pseudomonas aeruginosa 16.9\%. Another study carried out in Malawi [22] also found Proteus mirabilis to be the most prevalent aerobic bacterial entity, with $\mathrm{P}$ aeruginosa, and $\mathrm{S}$ aureus as second and third, respectively. In our study, the other bacterial pathogens included; providencia stuartii, Providencia rettgeri, Klebsiella pneumonia, Escherichia coli, Enterobacter cloacae and Morganella morgana were the less commonly involved (1.1-4.2\%). This finding were in line with previous study by Tesfa et al. who reported that, other gram-negative rods under the Enterobacteriaceae (Citrobacter species, Providencia species, Serratia species, Enterobacter species, and Morganella species) account for 7-11\%, but separately they account for less than 5\% [18]. In the current study, fungi were also isolated, the most common was Candida species $6(6.3 \%)$, followed by Aspergillus species $5(5.3 \%)$, this finding were similar to previous study by Tesfa et al. who found out that fungal pathogens like Candida species and Aspergillus species account for 6\% (3-8\%) of the etiology for otitis media [18]. The proportions of different organisms isolated vary from study to study. These differences may be related to sample size and geographical variations. Of more interest in our study is the microbial pathogens of Pseudomonas aeruginosa, Staphylococcus aureus and Candida species, were most common among female patients, while Proteus mirabilis, Klebsiella pneumonia, Bacteroides melaninogenicus, Escherichia coli were more frequently encountered among male patients. The relation was not found to be statistically significant. In our study, the most common isolate in children was Staphylococcus aureus whereas, Proteus mirabilis, Klebsiella pneumonia, Bacteroides melaninogenicus, Escherichia coli were never fined in children.

Antibiotic susceptibility patterns are important guideline for proper treatment of CSOM. In present study, the antimicrobial profile of the major isolates of Pseudomonas aeruginosa showed relatively resistance to gentamicin and neomycin, but the isolates were revealed maximum sensitivity to ciprofloxacin $(93.3 \%)$, followed by polymyxin $(90.0 \%)$, ceftazidime $(83.3 \%)$ and amikacin $(73.3 \%)$. The sensitivity of Pseudomonas aeruginosa to ciprofloxacin and amikacin in our study is consistent with other reports $[16,23,24]$. Whereas the antimicrobial profile of the isolates Staphylococcus aureus was revealed maximum sensitivity to ciprofloxacin (95.8\%), followed by amoxil/clavulanic acid (83.3\%), cephalexin, gentamicin, chloramphenicol (79.2\%) each, neomycin (75.0\%) and erythromycin (70.8\%). The sensitivity of Staphylococcus aureus to ciprofloxacin in our study is consistent with other reports [16]. On the other hand Proteus mirabilis and other isolates including providencia stuartii, Providencia rettgeri, Klebsiella pneumonia, Escherichia coli, Enterobacter cloacae and Morganella morgana showed high level of sensitivity to ciprofloxacin, ceftazidime and amikacin gentamicin, neomycin, trimethoprim sulphamethoxazole. Overall, in our study the most of bacterial isolates showed excellent in vitro susceptibility patterns. This could relate to that the most of these infections are community acquired infection and does not show the multi-resistant pattern of nosocomial infection. Ciprofloxacin appeared to be the most effective drug against all causative organisms (Gram-positive and Gram-negative) isolated in our study. Quinolones are the treatment of choice for CSOM; they are equally or more effective as aminoglycosides and lack the risk of ototoxicity, they are effective in resolving otorrhoea and eliminating the microorganisms [25]. Ciprofloxacin was found to be the most effective drug as it has been reported in other studies [16, 17, 26]. Beta-lactam antipseudomonal drugs (ceftazidime) also effective for treatment CSOM [26].

\section{CONCLUSION}

Over all, these finding shows that the main otopathogens responsible for tubotympanic CSOM in Libya were Pseudomonas aeruginosa followed by Staphylococcus aureus and Proteus mirabilis. Our finding highlight the importance of a continuous and periodic evaluation of microbial pathogens causing tubothympanic CSOM and their susceptibility patterns to antimicrobial drugs, the outcome will guide the clinician for choosing the appropriate treatment regimen and prevention of the emergence of resistant strain as well as can minimize complication that require surgery. Ciprofloxacin was shown to be the most effective antibiotic, with high sensitivities for the most commonly isolated Gram-positive and Gram-negative bacteria associated with CSOM.

\section{REFERENCES}

1. Acuin, J. (2004). World Health Organization. Dept. of Child and Adolescent Health and Development \& WHO Programme for the Prevention of Blindness and Deafness. Chronic suppurative otitis media: burden of illness and management options. Geneve: World Health Organization. http://www.who.int/iris/handle/10665/42941.

2. Monasta, L., Ronfani, L., Marchetti, F., Montico, M., Brumatti, L. V., Bavcar, A., \& Tamburlini, G. (2012). Burden of disease caused by otitis media: systematic review and global estimates. PloS one, 7(4), e36226.

3. Shenoi, P.M. (2018). Management of chronic suppurative otitis media. Scott Brown's textbook of Otorhinolaryngology. 8th Edition. 2:215. 3. Fliss DM, Shoham I, Leiberman A, Dagan.

4. Baldwin, R. L., \& Aland, J. (1990). The effects of povidone-iodine preparation on the incidence of posttympanostomy otorrhea. Otolaryngology-Head and Neck Surgery, 102(6), 631-634.

5. Bluestone, C.D. (2000). Pathogenesis of otitis media: role of Eustachian tube. Paediatr Infec Dis J, 19 (5):281-291. 
6. Fliss, D. M., Shoham, I. L. A. N. A., Leiberman, A. L. B. E. R. T. O., \& Dagan, R. (1991). Chronic suppurative otitis media without cholesteatoma in children in southern Israel: incidence and risk factors. The Pediatric infectious disease journal, 10(12), 895-899.

7. Prakash, R., Juyal, D., Negi, V., Pal, S., Adekhandi, S., Sharma, M., \& Sharma, N. (2013). Microbiology of chronic suppurative otitis media in a tertiary care setup of Uttarakhand state, India. North American journal of medical Sciences, 5(4), 282.

8. Loy, A. H. C., Tan, A. L., \& Lu, P. K. S. (2002). Microbiology of chronic suppurative otitis media in Singapore. Singapore medical journal, 43(6), 296-299.

9. Kumar, R., Srivastava, P., Sharma, M., Rishi, S., Nirwan, S., \& Hemwaniand, K. (2013). Isolation and antimicrobial sensitivity profile of bacterial agents in chronic suppurative otitis media patients at NIMS Hospital. Jaipur. IJPBS, 3(4), 265-9.

10. Grevers, G. (2010). Challenges in reducing the burden of otitis media disease: an ENT perspective on improving management and prospects for prevention. International journal of pediatric otorhinolaryngology, 74(6), 572-577.

11. Agrawal, A., Kumar, D., Goyal, A., Goyal, S., Singh, N., \& Khandelwal, G. (2013). Microbiological profile and their antimicrobial sensitivity pattern in patients of otitis media with ear discharge. Indian journal of otology, 19(1), 5.

12. Cheesbrough, M. (1981). Medical laboratory manual for tropical countries (Vol. 1). M. Cheesbrough, 14 Bevills Close, Doddington, Cambridgeshire, PE15 OTT.

13. Cockerill, F.R., Wikler, M.A., Bush, K., Dudley, M.N., Eliopoulos, G.M., Hardy, D.J. (2011). Performance Standards for Antimicrobial Susceptibility Testing Twenty-First Informational Supplement.

14. Govindaraj, S., Iype, J. V., Srinivasa, V., \& Jayendiran, S. (2019). Bacteriological profile and their antibiotic susceptibility pattern in chronic suppurative otitis media (TTD) in a tertiary care hospital. International Journal of Otorhinolaryngology and Head and Neck Surgery, 5(4), 871.

15. Shyamala, R., \& Reddy, P. S. (2012). The study of bacteriological agents of chronic suppurative otitis mediaaerobic culture and evaluation. J Microbiol Biotechnol Res, 2, 152-62.

16. Mofatteh, M. R., Moghaddam, F. S., Yousefi, M., \& Namaei, M. H. (2018). A study of bacterial pathogens and antibiotic susceptibility patterns in chronic suppurative otitis media. The Journal of Laryngology \& Otology, 132(1), 41-45.

17. Xu, J., Du, Q., Shu, Y., Ji, J., \& Dai, C. (2020). Bacteriological Profile of Chronic Suppurative Otitis Media and Antibiotic Susceptibility in a Tertiary Care Hospital in Shanghai, China. Ear, Nose \& Throat Journal, 0145561320923823.

18. Tesfa, T., Mitiku, H., Sisay, M., Weldegebreal, F., Ataro, Z., Motbaynor, B., ... \& Teklemariam, Z. (2020). Bacterial otitis media in sub-Saharan Africa: a systematic review and meta-analysis. BMC infectious diseases, 20(1), 1-12.

19. Hailu, D., Mekonnen, D., Derbie, A., Mulu, W., \& Abera, B. (2016). Pathogenic bacteria profile and antimicrobial susceptibility patterns of ear infection at Bahir Dar Regional Health Research Laboratory Center, Ethiopia. SpringerPlus, 5(1), 1-6.

20. Kazeem, M. J., \& Aiyeleso, R. (2016). Current bacteriological profile of chronic suppurative otitis media in a tertiary facility of Northern Nigeria. Indian Journal of Otology, 22(3), 157.

21. Ogah, S., \& Ogah, J. (2016). Aerobic bacteriology of chronic Suppurative otitis media (CSOM) in Federal Medical Centre Lokoja, Nigeria. Nig J Pure Appl Sci, 29: 2695-99.

22. Chirwa, M., Mulwafu, W., Aswani, J. M., Masinde, P. W., Mkakosya, R., \& Soko, D. (2015). Microbiology of chronic suppurative otitis media at queen Elizabeth central hospital, Blantyre, Malawi: a cross-sectional descriptive study. Malawi Medical Journal, 27(4), 120-124.

23. Agrawal, R., Khatri, P., Parihar, R., \& Shah, H. (2017). Microbial assessment of chronic suppurative otitis media in a tertiary care center of Rajasthan. Int J Health Sci Res, 7(2), 120-126.

24. Nazir, A., \& Kadri, S. M. (2014). Aerobic bacteriology of chronic suppurative otitis media: a hospital based study. Int J Res Med Sci, 2(4), 1521-5.

25. Harris, A. S., Elhassan, H. A., \& Flook, E. P. (2016). Why are ototopical aminoglycosides still first-line therapy for chronic suppurative otitis media? A systematic review and discussion of aminoglycosides versus quinolones. The Journal of laryngology and otology, 130(1), 2.

26. Abraham, Z. S., Ntunaguzi, D., Kahinga, A. A., Mapondella, K. B., Massawe, E. R., Nkuwi, E. J., \& Nkya, A. (2019). Prevalence and etiological agents for chronic suppurative otitis media in a tertiary hospital in Tanzania. BMC research notes, 12(1), 1-6.

CITATION: Khalled M Saeed et al (2021). Antimicrobial Drugs Susceptibility Pattern of Bacterial Pathogens Isolated from Cases of Tubotympanic Type of Chronic Suppurative Otitis Media (CSOM) in Tripoli-Libya. South Asian Res $J$ App Med Sci, 3(2), 6-11. 